\title{
Comparative efficacy and safety of local and systemic methotrexate injection in cesarean scar pregnancy
}

Ping Peng'

Ting Gui'

Xinyan Liu'

Weilin Chen'

Zhenzhen Liu ${ }^{2}$

'Department of Obstetrics and Gynecology, ${ }^{2}$ Department of Ultrasonography, Peking Union Medical College Hospital, Peking Union Medical College, Chinese Academy of Medical Sciences, Beijing, People's Republic of China
This article was published in the following Dove Press journal:

Therapeutics and Clinical Risk Management

27 January 2015

Number of times this article has been viewed
Objective: To investigate the efficacy of methotrexate (MTX) injection in treatment of cesarean scar pregnancy (CSP).

Method: A randomized controlled study was performed in 104 CSP patients receiving either local or systemic MTX injection at the Peking Union Medical College Hospital from the year 2008 to 2013.

Results: Complete cure was defined as regression of ultrasonographic findings and normalization of serum $\beta$-hCG within 60 days. It was regarded as delayed cure if additional dilation and curettage (D\&C) was needed. The overall cure rate (complete cure plus delayed cure) was $69.2 \%$ versus $67.3 \%$ for local injection versus systemic administration $(P>0.05)$. The median time for serum $\beta$-hCG remission and uterine mass disappearance after systemic administration (42 [21-69] days and 40 [20-67] days) were significantly lower than those receiving local injection (56 [24-92] days and 53 [23-88] days), with $P=0.029$ and 0.046 , respectively. The mean pretreatment serum $\beta$-hCG (human chorionic gonadotropin) level and lesion size in cured group $(21,941 \pm 18,351 \mathrm{mIU} / \mathrm{mL}$ and $2.9 \pm 1.3 \mathrm{~cm}$, respectively) were significantly lower than those in the failed group $(37,047 \pm 30,864 \mathrm{mIU} / \mathrm{mL}$ and $3.6 \pm 1.3)$ with $P=0.038$ and 0.044 , respectively.

Conclusion: MTX injection is effective in CSP treatment. Systemic administration shows similar overall cure rate compared to local injection, but requires shorter time for serum $\beta$-hCG remission and uterine mass disappearance.

Keywords: cesarean scar pregnancy, methotrexate injection, local, systemic

\section{Introduction}

Cesarean scar pregnancy (CSP) is a special form of ectopic pregnancy resulting from the implantation of an embryo on previous cesarean scar. ${ }^{1,2}$ It constitutes $6.1 \%$ of all ectopic pregnancies. ${ }^{3}$ With the increasing prevalence of cesarean section (CS) birth and the widespread use of ultrasonography in early gestation, the rate of CSP had increased exponentially. ${ }^{4}$

Blind uterine curettage may lead to massive hemorrhage in CSP since the uterine contraction is very weak in the scar, and hysterectomy would be necessary for saving the life of patients. As CSP is a condition in reproductive age, the conservation of fertility is the main concern for the patients. Invasive and radical treatment, such as hysterectomy, has recently been replaced by minimally invasive therapies. ${ }^{5}$

Methotrexate (MTX) is an antimetabolite drug that has been used successfully in conditions associated with trophoblastic proliferation. Systemic MTX is a standard treatment for tubal and cervical ectopic pregnancy if the gestational age is less than 9 weeks, the embryo size is smaller than $10 \mathrm{~mm}$, no cardiac activity is seen, and the 
serum $\beta$-hCG (human chorionic gonadotropin) levels are less than $10,000 \mathrm{mIU} / \mathrm{mL} .{ }^{6}$ The experience gained from the treatment of tubal ectopic pregnancy with MTX has led some investigators to consider MTX as a treatment option in CSP. Studies have shown a good response for MTX at a dose of $50 \mathrm{mg} / \mathrm{m}^{2}$, especially when $\beta$-hCG level is less than $5,000 \mathrm{mIU} / \mathrm{mL} \cdot{ }^{7,8}$

So far, most investigations concerning MTX treatment in CSP are retrospective analyses. At present, there are two approaches for MTX usage: systemic injection and local injection (ultrasound-guided intragestational sac injection). Are there any differences in therapeutic efficacy and clinical outcome associated with these two approaches? How do we make a choice in clinical practice? Considering these questions, our objectives in this study are therefore threefold: 1) to investigate the MTX treatment in CSP patients prospectively at the Peking Union Medical College Hospital (PUMCH); 2) to compare the efficacy between local injection and systemic administration of MTX, and 3) to analyze the factors in favor of patient prognosis, providing reference for screening candidates for MTX therapy.

\section{Materials and methods}

Our research was approved by the Ethics Committee of PUMCH, and written informed consent from each patient was obtained before treatment. From the year 2008 to 2013, 225 patients with CSP were admitted to $\mathrm{PUMCH}$, among whom 195 patients met our inclusion criteria. Ninety-one patients refused MTX treatment, and finally 104 patients were enrolled and randomized 1:1 to a MTX treatment of systemic intramuscular injection or local intragestational sac injection (Figure 1).

The inclusion criteria were as follows: 1) diagnosis of CSP was confirmed by two ultrasound specialists independently, and 2) patients with CSP did not present with heavy vaginal bleeding when admitted to the hospital.

The diagnosis of CSP was based on the criteria postulated by Godin et al including 1) well-formed gestational sac in the myometrium of the lower uterine segment, 2) the presence of an empty uterine and cervical cavity, and 3) lack of continuity of myometrial image between the bladder and the gestational sac. ${ }^{9}$

Patients were counseled about the risks of the condition and management alternatives, including potential benefits and risks. Baseline $\beta$-hCG levels were noted. Gestational age was determined according to the last menstrual period. Two parameters, sac dimension and crown-rump length, were used to determine gestational age in situations when patients could not remember their last menstrual period, or when a discrepancy existed.

After appropriate counseling, patients were referred to our MTX treatment center. Both patients and doctors in the outpatient clinic were blinded to group allocation. Enrolled patients were then sequentially numbered. Patients labeled with odd numbers were given systemic intramuscular injection of MTX, while patients labeled with even numbers received the local intragestational sac injection of MTX, both at a dose of $50 \mathrm{mg} / \mathrm{m}^{2}$.

On the seventh day after the first MTX injection, if the decrease in serum $\beta$-hCG level was less than $15 \%$, MTX injection was then repeated. On the 14th day, if the serum $\beta$-hCG level was still not reduced by over $15 \%$, or even increased, MTX treatment was considered failed, and uterine artery embolization (UAE) was performed followed by dilation and curettage (D\&C). If heavy bleeding occurred during D\&C, laparotomy with surgical resection of CSP or possible hysterectomy, would be needed. On the 60th day, if the gestational sac remarkably diminished but persistently existed, no matter whether the $\beta$-hCG level returned to normal or not, D\&C would be performed. ${ }^{10,11}$

Complete cure was defined as regression of ultrasonographic findings and normalization of serum $\beta-\mathrm{hCG}$ within 60 days. Complete sonographic resolution of CSP was defined as the absence of gestational sac, hyperechogenic chorionic rim, and any other echodensities under the cesarean scar, along with regular endometrial line in lower uterine segment at transvaginal ultrasonogrphy. It was regarded as delayed cure if additional D\&C was needed when ultrasound or serum $\beta$-hCG did not become normal within 60 days. Complete cure plus delayed cure were considered as treatment success. UAE plus D\&C that was performed due to unsatisfactory reduction or increase of serum $\beta$-hCG was considered as MTX treatment failure.

For follow-up, serum $\beta$-hCG testing was performed every 3-4 days until the titers decreased to $50 \%$ of pretreatment levels, and weekly after until the titers returned to normal levels ( $<5 \mathrm{IU} / \mathrm{L})$.

For statistical analysis, Fisher's exact test and student's $t$-test were used to analyze the data, and a $P$-value $<0.05$ was considered statistically significant.

\section{Results}

\section{Patient information}

From 2008 to 2013, 225 patients with CSP were admitted into PUMCH, accounting for $6.7 \%(225 / 3,325)$ of all ectopic pregnancy, similar to the data of previous studies. 


\section{CONSORT \\ TRANSPARENT REPORTING of TRIALS}

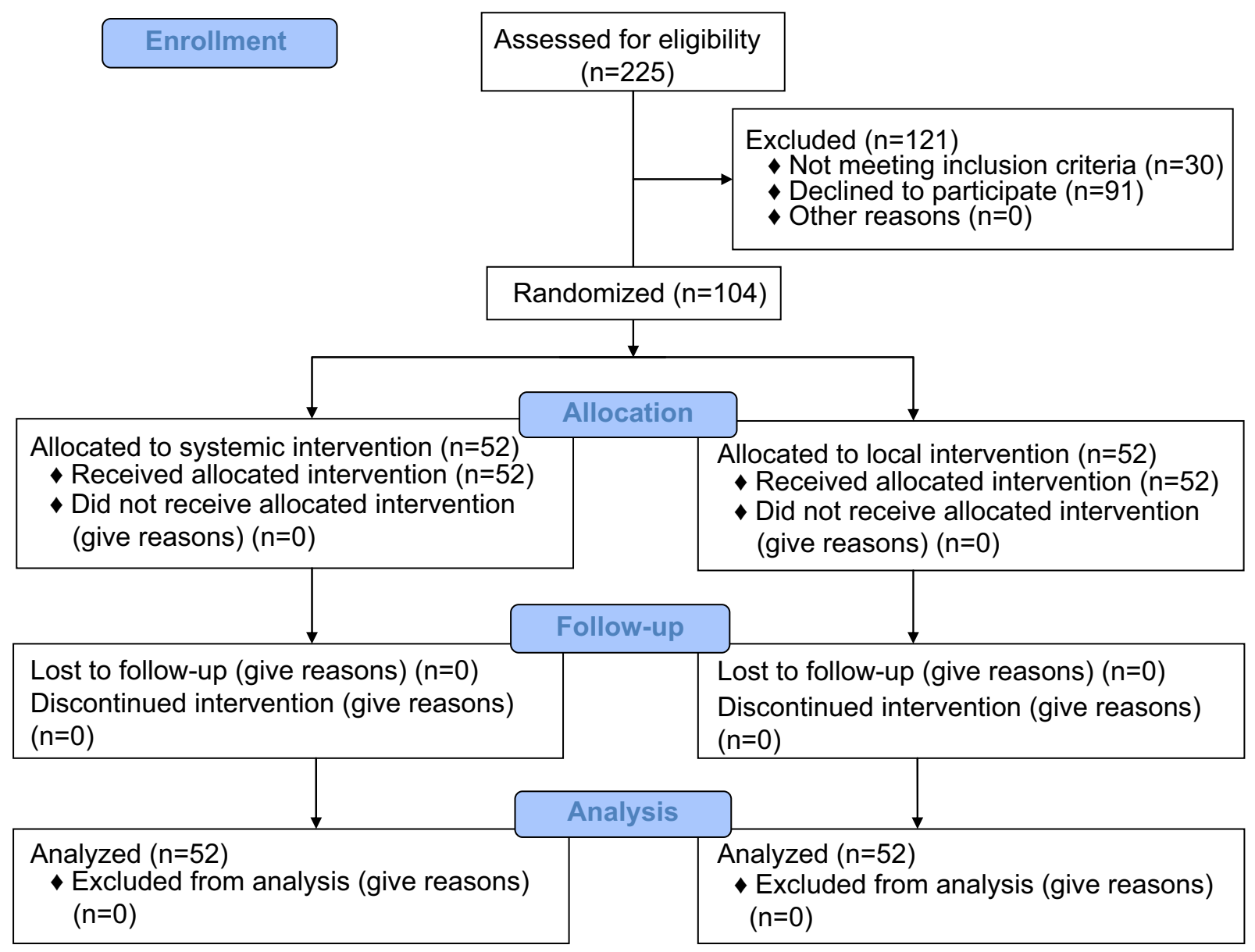

Figure I Consort flow diagram.

One-hundred and four patients were included in our research. The mean maternal age was $32.6 \pm 4.9$ years, with a median gravidity of 4 (1-6) and a median parity of 1 (1-3). Ninety-two patients had one prior CS $(88.5 \%, 92 / 104)$, and the others had two previous CS $(11.5 \%, 12 / 104)$. The average time interval between current CSP and previous CS was $53.9 \pm 45.1$ months.

Specifically, for the local injection group and systemic administration group, the mean maternal age was $32.3 \pm 4.7$ and $32.7 \pm 5.0$ years, the mean gestational age at diagnosis was $55 \pm 20.2$ and $56.3 \pm 22.1$ days, and the average time interval between current CSP and previous CS was $52.4 \pm 50.5$ and $54.4 \pm 43.4$ months, respectively. In addition, the mean pretreatment serum $\beta$-hCG level was $35,472 \pm 28,263$ and $22,532 \pm 19,547 \mathrm{mIU} / \mathrm{mL}$, the mean lesion size was $3.0 \pm 1.4$ and $3.1 \pm 1.6 \mathrm{~cm}$, and the mean scar thickness in the lower segment of uterus was $2.9 \pm 1.6$ and $2.6 \pm 1.5 \mathrm{~mm}$, for local injection group versus systemic administration group. All the clinical parameters between these two groups showed no significant differences (Table 1).

\section{Clinical outcome}

According to the criteria of treatment success mentioned above, 71 (71/104, 66.4\%) patients were cured after MTX treatment, among whom 39 patients were completely cured after MTX monotherapy and 32 patients were delayed-cured with additional D\&C. The other 33 patients were not sensitive to MTX therapy and underwent UAE plus D\&C, among whom 4 patients received laparotomy to remove the uterine scar lesion because of excessive bleeding. The median time interval between the first MTX injection and the normalization of serum $\beta$-hCG was 46 (21-92) days. The median time 
Table I Demographic information of patients with cesarean scar pregnancy

\begin{tabular}{llll}
\hline Parameters & Local injection (mean \pm SD) & Systemic administration (mean \pm SD) & P-value \\
\hline Age (years) & $32.3 \pm 4.7$ & $32.7 \pm 5.0$ & 0.755 \\
Interval between current CSP and last cesarean (months) & $52.4 \pm 50.5$ & $54.4 \pm 43.4$ & 0.856 \\
Gestational age at diagnosis (days) & $55 \pm 20.2$ & $56.3 \pm 22.1$ & 0.796 \\
Pretreatment serum $\beta-h C G$ level $(\mathrm{mlU} / \mathrm{mL})$ & $35,472 \pm 28,263$ & $22,532 \pm 19,547$ & 0.071 \\
Uterine mass size $(\mathrm{cm})$ & $3.0 \pm 1.4$ & $3.1 \pm 1.6$ & 0.692 \\
Uterine scar thickness $(\mathrm{mm})$ & $2.9 \pm 1.6$ & $2.6 \pm 1.5$ & 0.363 \\
\hline
\end{tabular}

Abbreviations: CSP, cesarean scar pregnancy; hCG, human chorionic gonadotropin.

for uterine scar disappearance was 43 (20-88) days. The mean hospitalization time was $11.4 \pm 6.8$ days, and the mean hospitalization fee was 5,335.4 $\pm 6,027.2$ RMB.

Specifically, for the local injection group, 19 patients (19/52,36.5\%) got complete cure, 17 patients $(17 / 52,32.7 \%)$ got delayed cure, and the other 16 patients $(16 / 52,30.7 \%)$ failed the treatment, with an overall cure rate of $69.2 \%$. In comparison, for the systemic administration group, 20 patients $(20 / 52,38.5 \%)$ were completely cured, 15 patients $(15 / 52,28.8 \%)$ got delayed cure, and the other 17 patients $(17 / 52,32.7 \%)$ were not sensitive to MTX treatment, with an overall cure rate of $67.3 \%$. Statistically, the cure rates for the two groups have no significant difference (Table 2).

The median time for serum $\beta$-hCG remission was 56 (24-92) and 42 (21-69) days, and the mean time for uterine mass disappearance was 53 (23-88) and 40 (20-67) days, for local injection group vs systemic administration group. Systemic administration showed superiority in serum $\beta$-hCG remission and uterine mass disappearance compared with local injection, with $P=0.029$ and 0.046 , statistically. The mean hospitalization time was $12.4 \pm 6.1$ and $10.9 \pm 7.0$ days, and the mean hospitalization fee was 4,976.3 $\pm 4,339.4$ and 4,384.4 $\pm 4,009.7$ RMB for local injection group vs systemic administration group, without significant differences (Table 2).

Regarding treatment side effects, 1 patient receiving local injection of MTX presented bone marrow suppression (white blood cell $1.37 \times 10^{9} / \mathrm{L}$ and neutrophil $0.51 \times 10^{9} / \mathrm{L}$ ). One patient in the local injection group and 1 patient in the systemic administration group appeared to have oral ulceration. Both recovered several days later after symptomatic treatment. Four patients who failed the MTX therapy encountered severe bleeding $(>200 \mathrm{~mL})$ during D\&C after UAE, one in local injection group and three in systemic administration group.

\section{Analysis of potential factors in favor of treatment success}

In our study, the patients were divided into two groups: 71 in the cured group and 33 in the failed group. The mean pretreatment serum $\beta$-hCG level of the cured group was $21,941 \pm 18,351$ $\mathrm{mIU} / \mathrm{mL}$, which was much lower than that of the failed group $(37,047 \pm 30,864 \mathrm{mIU} / \mathrm{mL})(P=0.038)$. The mean lesion size of the cured group was $2.9 \pm 1.3$, which was significantly smaller than that in the failed group 3.6 $\pm 1.3(P=0.044)$ (Table 3$)$.

\section{Discussion}

Pregnant women with a prior cesarean delivery should be aware of the possibility of CSP, which is a type of ectopic gestation that may lead to life-threatening heavy bleeding and uterine rupture due to abnormally adherent placenta. The diagnosis mainly relies on ultrasound examination and magnetic resonance imaging, if necessary. The goals of treatment are termination of pregnancy, reduction of hemorrhage, and prevention of uterus rupture. The treatment options for CSP vary from expectant management to $\mathrm{D} \& \mathrm{C}$ after uterine artery embolization, and from local resection of CSP lesion to hysteroscopy. ${ }^{12}$

Considering successful reported cases of multiple pregnancy reduction and conservative treatments in ectopic pregnancy, this prospective study was designed to evaluate the clinical effects of MTX therapy in women with CSP who were randomly treated with MTX either locally (intragestational sac injection) or systemically.

Table 2 Clinical outcome of local injection and systemic administration of MTX

\begin{tabular}{llll}
\hline Clinical outcome & Local injection & Systemic administration & P-value \\
\hline Overall cure rate (\%) & $69.2 \%$ & $67.3 \%$ & 0.232 \\
Time for serum $\beta$-hCG remission (days) & $56(24-92)$ & $42(21-69)$ & 0.029 \\
Time for uterine mass disappearance (d) & $53(23-88)$ & $40(20-67)$ & 0.046 \\
Hospitalization time (days) & $12.4 \pm 6.1$ & $10.9 \pm 7.0$ & 0.396 \\
Hospitalization fee (RMB) & $4,976.3 \pm 4,339.4$ & $4,384.4 \pm 4,009.7$ & 0.583 \\
\hline
\end{tabular}

Note: Data is presented as median with range and mean \pm SD.

Abbreviations: MTX, methotrexate; hCG, human chorionic gonadotropin. 
Table 3 Analysis of potential factors in favor of MTX treatment success

\begin{tabular}{llll}
\hline Potential factors & Cured $(\mathbf{n}=\mathbf{7 l})$ (mean $\pm \mathbf{S D})$ & Failed $(\mathbf{n}=\mathbf{3 3})(\mathbf{m e a n} \pm \mathbf{S D})$ & $\mathbf{P}$-value \\
\hline Pretreatment serum $\beta$-hCG level $(\mathrm{mlU} / \mathrm{mL})$ & $21,941 \pm 18,35 I$ & $37,047 \pm 30,864$ & 0.038 \\
Uterine mass size $(\mathrm{cm})$ & $2.9 \pm 1.3$ & $3.6 \pm 1.3$ & 0.044 \\
Uterine scar thickness $(\mathrm{mm})$ & $2.6 \pm 1.4$ & $2.9 \pm 1.7$ & 0.256 \\
\hline
\end{tabular}

Abbreviations: MTX, methotrexate; hCG, human chorionic gonadotropin.

In our study, 225 patients with CSP were admitted into PUMCH within 5 years, accounting for $6.7 \%$ (225/3325) of all ectopic pregnancy, similar to the data of previous studies. Seventy-one patients $(71 / 104,66.4 \%)$ obtained treatment success, while $33(33 / 104,33.6 \%)$ patients were not sensitive to MTX therapy and underwent UAE plus D\&C, among whom 4 patients received laparotomy to remove the uterine scar lesion because of excessive bleeding. The results of our study are consistent with those of previous research. Kutuk et al reported $100 \%$ cure rate in 13 patients treated with systemic multidose MTX therapy. ${ }^{13}$ In the study conducted by Wang et al $76.2 \%$ success and $19 \%$ hysterectomy rates were observed in patients with CSP who were treated with systemic MTX monotherapy. ${ }^{14}$ However, another study conducted by Lian et al showed a high failure rate of systemic administration of MTX, as 12 of 21 patients needed additional UAE combined with local MTX..$^{15}$ In general, MTX therapy success can be explained by the following facts: 1) the treatment protocol included multiple doses of MTX with short intervals; 2) the gestational age was relatively early at diagnosis; and 3) MTX treatment was implemented early without an unsuccessful first-line treatment attempt. ${ }^{13}$ In support of this, TimorTritsch et al suggested that earlier diagnosis and treatment rather than later showed an improved outcome, even though treatment modalities with slightly higher complication rates were used in very early gestation. ${ }^{4}$ In our research, for patients whose serum $\beta$-hCG level was decreased below $15 \%$ of the pretreatment level, additional MTX administration was delivered to enhance the effects, and most patients were diagnosed with CSP at an average of 8 weeks.

So far, most research has been on the efficacy of systemic administration of MTX in CSP, while studies focusing on other delivery methods such as local intragestational sac injection have been scarce. Our study, for the first time, explored the differences in efficacy between the local injection and systemic administration of MTX. Our results indicate that systemic administration of MTX shows similar overall cure rate, hospitalization time, and fee compared to local injection, but requires shorter time for serum $\beta$-hCG remission and uterine mass disappearance.

At a common dosage of $50 \mathrm{mg} / \mathrm{m}^{2}$, MTX therapy has several side effects, such as nausea, oral ulceration, bone marrow depression, severe bleeding, and uterine rupture In our study group, complications were mild and well tolerated, mainly including oral ulceration and bone marrow depression. Patients recovered several days after symptomatic treatment. Since only one patient presented with bone marrow depression and two patients complained oral ulceration, statistical analyses could not be performed.

MTX therapy failure is often suggested to be associated with high $\beta$-hCG level at presentation, deep implantation of the amniotic sac, advanced gestational age, and high vascularity around the gestational sac. ${ }^{16}$ To better screen candidates for MTX therapy, we then analyzed the potential factors that favor patient prognosis. The pretreatment serum $\beta$-hCG level and the uterine mass size in the treatment success group were significantly lower than those in the treatment failure group. Our data suggest that MTX therapy is more feasible in patients with lower serum $\beta$-hCG level $(<20,000 \mathrm{mIU} / \mathrm{mL})$ and smaller lesion $(<3.0 \mathrm{~cm}$ in diameter $)$.

The main disadvantage of systemic MTX therapy is prolonged hospitalization, especially in patients presenting with mild vaginal bleeding. With the increased experience, patients can be followed as outpatients when they are suitable for outpatient management under strict instructions.

\section{Conclusion}

Generally, MTX injection is effective in the treatment of CSP. Systemic administration shows similar overall cure rate compared with local injection, but requires shorter time for serum $\beta$-hCG remission and uterine mass disappearance.

\section{Acknowledgement}

This study was supported by the Capital Medical Development Foundation of China (No 2009-2004).

\section{Disclosure}

The authors report no conflicts of interest in this work.

\section{References}

1. Jurkovic D, Hillaby K, Woelfer B, Lawrence A, Salim R, Elson CJ. First trimester diagnosis and management of pregnancies implanted into the lower uterine segment cesarean section scar. Ultrasound Obstet Gynecol. 2003;21:220-227.

2. Jurkovic D, Hillaby K, Woelfer B, Lawrence A, Salim R, Elson CJ. Cesarean scar pregnancy. Ultrasound Obstet Gynecol. 2003;21:310. 
3. Timor-Tritsch IE, Monteagudo A, Santos R, Tsymbal T, Pineda G, Arslan AA. The diagnosis, treatment, and follow-up of cesarean scar pregnancy. Am J Obstet Gynecol. 2012;207:44.e1-13.

4. Timor-Tritsch IE, Monteagudo A. Unforeseen consequences of the increasing rate of cesarean deliveries: early placenta accreta and cesarean scar pregnancy. A review. Am J Obstet Gynecol. 2012;207:14-29.

5. Litwicka K, Greco E. Cesarean scar pregnancy: a review of management options. Curr Opin Obstet Gynecol. 2011;23:415-421.

6. Rotas MA, Haberman S, Levgur M. Cesarean scar ectopic pregnancies: etiology, diagnosis, and management. Obstet Gynecol. 2006;107:1373-1381.

7. Shufaro Y, Nadjari M. Implantation of a gestational sac in a cesarean section scar. Fertil Steril. 2001;75:1217.

8. Ravhon A, Ben-Chetrit A, Rabinowitz R, Neuman M, Beller U. Successful methotrexate treatment of a viable pregnancy within a thin uterine scar. Br J Obstet Gynaecol. 1997;104:628-629.

9. Godin PA, Bassil S, Donnez J. An ectopic pregnancy developing in a previous caesarian section scar. Fertil Steril. 1997;67:398-400.

10. Li C, Li C, Feng D, Jia C, Liu B, Zhan X. Transcatheter arterial chemoembolization versus systemic methotrexate for the management of cesarean scar pregnancy. Int J Gynaecol Obstet. 2011;113:178-182.
11. Wu X, Zhang X, Zhu J, Di W. Caesarean scar pregnancy: comparative efficacy and safety of treatment by uterine artery chemoembolization and systemic methotrexate injection. Eur J Obstet Gynecol Reprod Biol. 2012;161:75-79.

12. Ash A, Smith A, Maxwell D. Caesarean scar pregnancy. BJOG. 2007;114:253-263.

13. Kutuk MS, Uysal G, Dolanbay M, Ozgun MT. Successful medical treatment of cesarean scar ectopic pregnancies with systemic multidose methotrexate: single-center experience. J Obstet Gynaecol Res. 2014;40:1700-1706.

14. Wang JH, Xu KH, Lin J, Xu JY, Wu RJ. Methotrexate therapy for cesarean section scar pregnancy with and without suction curettage. Fertil Steril. 2009;92:1208-1213.

15. Lian F, Wang Y, Chen W, et al. Uterine artery embolization combined with local methotrexate and systemic methotrexate for treatment of cesarean scar pregnancy with different ultrasonographic pattern. Cardiovasc Intervent Radiol. 2012;35:286-291.

16. Lam PM, Lo KW, Lau TK. Unsuccessful medical treatment of cesarean scar ectopic pregnancy with systemic methotrexate: a report of two cases. Acta Obstet Gynecol Scand. 2004;83:108-111.
Therapeutics and Clinical Risk Management

\section{Publish your work in this journal}

Therapeutics and Clinical Risk Management is an international, peerreviewed journal of clinical therapeutics and risk management, focusing on concise rapid reporting of clinical studies in all therapeutic areas, outcomes, safety, and programs for the effective, safe, and sustained use of medicines. This journal is indexed on PubMed Central, CAS,

\section{Dovepress}

EMBase, Scopus and the Elsevier Bibliographic databases. The manuscript management system is completely online and includes a very quick and fair peer-review system, which is all easy to use. Visit http://www.dovepress.com/testimonials.php to read real quotes from published authors. 